Torkild Thellefsen.

Bent Sarensen (Eds.)

UMBERTO ECO

IN HIS

OWN WORDS

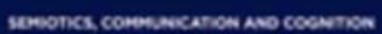

$\frac{4}{6}$

Publication Date: August 2017

Copyright year: 2017

ISBN 978-1-5015-0714-4
Umberto Eco in His Own Words

Ed. by Thellefsen, Torkild / Sørensen, Bent

Series: Semiotics, Communication and

Cognition [SCC] 19

Berlin: DE GRUYTER MOUTON 


\title{
Colour as Cultural Unit. Challenges and Developments
}

\begin{abstract}
When one utters a colour term one is not directly pointing to a state of the world (process of reference), but, on the contrary, one is connecting or correlating that term with a cultural unit or concept. The utterance of the term is determined, obviously, by a given sensation, but the transformation of the sensory stimuli into a percept is in some way determined by the semiotic relationship between the linguistic expression and the meaning or content culturally correlated to it. (How Culture Conditions the Colours We See, 1985: 160).
\end{abstract}

\section{Challenges and some solutions}

Colour as a cultural unit should include verbal and visual colours, colour and non-colour meanings (lexical and contextual), the whole information on the semantics of verbal and visual colours - synchronic and diachronic, cultural and social. Colour as a cultural unit should include meanings of colours in folk and religious rituals.

I have been involved with the problematics of colour for forty years. After scrupulous statistical research (I read 1000 pages five times), I made a general conclusion in my M.A. thesis (Colours in the novels of Emilian Stanev), which was an intuition: colour terms in the novels are a sign system which duplicates the information from the text. I recognised three types of colour terms - direct (later Basic Colour Terms, BCT), mediate (later - Prototype Terms, PT) and secondary (later - Rival Terms, RT).

I realized that this intuition that the colour words in the novels receive from the context meanings such as 'love', 'love passion', 'killing' for Red; 'pure”, 'aristocratism' for White; 'poisonous', 'dirty', 'afflicted' (in one novel), 'life', 'repose' (in different novels) for Green, etc. must be scientifically corroborated. Ergo, context causes categorization, similar to what Eco called 'The colours of national flags are not colours [...] they are expressions correlated to cultural units, and as such are strongly categorized.' (1985: 174). At the end of the $20^{\text {th }}$ century, I returned to Bulgarain novels (Almalech 2001) with rich scientific instruments.

In the middle seventies, Victor Turner was another source of inspiration for colour research for me and confirmation of the hypothesis that 'the colours [...]

Mony Almalech, New Bulgarian University, Bulgaria

DOI 10.1515/9781501507144-025 
are not colours' in the ritual symbolism of the African tribe Ndembu, e.g. for the red of blood: 'blood of animals', 'huntsmanship', 'meat'; the blood of parturition, of mother; the blood of all women, i.e. menstrual blood; the blood of murder or stabbing or killing [...] 'Red things belong to two categories, they act both for good and ill (these), are combined,' etc. (Turner 1966: 59-60).

Thus, the challenges were: 1 . In the novels we have words for colours; 2 . In the rituals the colours are visual; 3. Both are categorized with non-colour meanings, and some of these are similar.

In the early nineties I faced one more challenge in analysing visual colour. In my research on traditional marriage customs I found that a red bridal veil was the sign of the bride in Ancient Rome, Ancient Greece, the Ottoman bride in the 19-20 centuries, Christian brides in Slav ethnic territories, for Armenian, Jewish and Druse brides. (Almalech 1996). Brides of current China, India, and Nepal still keep their red dresses and veils, especially in rural districts. Regardless of religion, level of technology and social set-up, it appears that a red bridal veil was an universal sign for marriage for Europe and Asia. Apart from that, in traditional marriage there are four colours: Red - apotropaic; White - purity, clean, immaculate; Green - life; Gold - 1. Utilitarian value of wealth; 2 . Permit to the afterlife.

The next set of challenges I faced in my long-lasting research on colours relates to the Hebrew Bible and its translations, i.e. back to the verbal colours and worldview of Hebrew and other languages (Almalech 2006; 2010; 2013). Associated with this set of problems is another object of my interest, namely colours in advertisements where visual and verbal colours co-exist (Almalech 2011b).

Eco calls the non-colour meanings of colours "values" (1985: 174). For me, these "values" are the main goal of semiotic research on colour. To reach this goal is very difficult, because it needs a lot of pre-conditions, clarifications and an enormous scientific apparatus. We should take into account folklore, religious culture - in both diachronic and synchronic directions. Briefly - a large personal encyclopedia. By 2011, I abstained from using the term "cultural unit" about colour, because it is clear that in order to properly decode the semantic values of the colours a great personal encyclopedia is required. 'Values' like hope, health, love etc. are relevant in novels and rituals. How does it happen so that for flags 'the system of basic values to be expressed by colours is a limited one', but for rituals and novels - it is not so limited? 


\section{Steps/methods to overcome the problems}

First of all, we should recognize visual and verbal colour. The basic idea is that despite the many contributions hitherto there has been no clear differentiation in the semiotic status of visual and verbal colour. Eco (1985: 159) points the difference and, at the same time, the connection between visual and verbal colours:

We are dealing with verbal language in so far as it conveys notions about visual experiences, and we must, then, understand how verbal language makes the non-verbal experience recognizable, speakable and effable.

Visual colour is what we have access to by our visual perception. Verbal colour is when we use natural language to designate colour in natural language. Eco marked this feature of natural languages: 'the 3000 hues that [...] the Maori of New Zealand recognize and name by 3000 different terms' (Eco 1985: 168).

My linguo-semiotic approach includes knowledge of the paradigm of Berlin and Kay (1969), the World Colour Survey, led by Kay, and their critics; ${ }^{1}$ Norms of free association tests to BCT for different languages. Visual colours are perceived simultaneously or tactically. Verbal colours are subjected to linear ordering or the syntax of natural language.

The parameters of the environment and human anatomy and psychology dictate the formation of colour categories in the minds of humans via the so-called most typical examples or prototypes for colour. Prototype Theory was presented by Rosch (1972; 1973), Lakoff (1987) and Wierzbicka (1990). The prototypes are: Light or milk or snow for White; darkness or coals for Black; blood and/or fire/ flame for Red; sea and/or sky for Blue; the sun of midday for Yellow; all plants for Green. Prototypes are true for all races and peoples, regardless of the political and economic system and social structure, regardless of the degree of technological development. It is a universal phenomenon based on human anatomy and environmental conditions.

Reasons for such an approach provides the relationship of colours with the colour prototypes through which different cultures encode specific semantics in the rituals formed by the religious and scientific beliefs of an ethnic group. Studies of the rituals of different peoples give one reason to think about a small number of universal values, motivated by the strategy of ritual and its relationship with colour prototypes.

1 Avaiable at www1.icsi.berkeley.edu/wcs/ 
Just as diachronic changes are the mien of permanent semiosis for natural languages, changes in the language of colour during the centuries are something we can expect to happen.

Key rituals, as marriage, have been repeated for centuries without change. In current monotheistic states, in China, Nepal and India, a white "uniform" is the norm for bridal attire. The red dress, red veil, and red shoes are substituted by white ones. There are even some mixtures between the traditional and current marriage norms.

Obviously there is no marriage withought greenery. The modern 'white' version preserves this element. Gold has also been preserved in the norm as gold rings. Thus, only red has been eliminated from the ancient norm.

It is a quite popular understanding that a white dress and a white veil have the meaning 'moral and physical purity', 'virginity'. These meanings exist in both the traditional and the modern norm. When did the new association norm start? There are two women noted to have made the white wedding gown popular Anne of Brittany and Queen Victoria. The case with Anne of Brittany is the product of mythology. We can meet the opinion that she wore a white dress and a white veil to express her protest and disagreement with the marriage settlement to a French king, which put her and her district in obedience to the French crown. At that time the mourning colour for the king's family was white.

Queen Victoria wore an elegant all white gown to her wedding in 1840 and this started the trend towards wearing white for weddings. White was worn because people believed it represented affluence, virginity and purity. ${ }^{2}$

This change is diachronic. This does not mean, however, that contemporary fashion is deprived of meaning. In fact, white has the same meaning, which operates under the "white mourning" in ancient times and in different cultures purity. Thus, we have a diachronic change, which does not undermine the existence of colour language.

Quite an interesting phenomenon is documented in the Bible. The norm for the clothes of priests was postulated by Moses (13 $3^{\text {th }}$ century B.C.) for the Tabernacle. The clothes of priests constitute a colour Tetranom - blue [tekhèleth], purple [argamàn], scarlet [tolàat šanì], and fine linen [šeš]. It is a verbal specification with loan words, not by accident, for something which should be visual. The colour tetranom was retained in the First Temple but Solomon replaced linen-[šeš] with linen-[butz] in the $10^{\text {th }}$ century B.C. In the $6^{\text {th }}$ century B.C., the prophet Ezekiel postulated that priests should wear monocoloured clothes in the Second Temple - the entire tetranom was withdrawn. The single colour of linen

2 (www.vaaltriangleinfo.co.za/wedding_guide/wedding. Accessed August 2016) 
was named by another term - [pištìm]. The diachronic changes in terminology are a marker for the cultural and contextual circumstances that dictate these changes. The terminology for priest's clothes has a special status because before the story of Moses two other terms for linen clothes appear in the Biblical text [badìm] and [ketònet].

Diachronic changes in rituals and set terminologies are inevitable phenomena, just as they are for natural languages. In the case for the term linen in the Hebrew Bible, I formulated the reasons for the changes in Almalech 2011b. In the case of the white bridal veil and dress there is an anthropological and cultural explanation. The development of technologies at the end of the $19^{\text {th }}$ century and the resettlement of many villagers in towns lead to the illusion that people do not depend on nature - therefore red is no longer necessary for the protection of the bride from bad natural forces.

Current humanitarian knowledge is focused on colours in multimodal texts/ messages in an attempt to formulate a Visual communication grammar. Kress and van Leeuwen (2002) deal with visual colour by analysing colour speech and visual rhetoric, but they do not resort to a colour language. According to the authors, colour is metafunctional, characterised with ideational, interpersonal, and textual functions. In some cases colour fulfils these three metafunctions simultaneously (346), but it does not necessarily always do this. (350)

Kress and van Leeuwen (2002) recognise that there are two ways to produce the meaning of colours.

The first is psychological - by associations that come from the culture and the past, but also from present current advertising and brands. An important element is the context in which an association operates. The second way is to accept the visual qualities of colour - hue, saturation, purity, modulation, differentiation - as semantic distinguishing features. They are placed within the ideational, interpersonal and textual functions. (: 355$)$.

Thus, we enter the territory of the visual by the physical properties of colour, once -, and secondly, - into the social and individual cultures and tastes. The final result is not a list, a dictionary of meanings of colours. The biggest drawback remains the possibility of subjective evaluation (typical of humanitarian knowledge) of various factors, functions, and properties of colour. A high degree of complexity characterizes this system, despite its scholarly strictness. It is a fact that Prototype theory and the idea of colour as a cultural unit are not used by Kress and van Leeuwen.

Furthermore, the goal of Kress and van Leeuwen (1996; 2002) is to formulate a Visual communication grammar, and this neglects verbal colours. And for me, a very important question is "Are there shared meanings between visual and verbal colours?”. I presented a list of such meanings in Almalech 2011b. 
For me, treating colours as 'cultural units' by Eco (1985/1996) gives more freedom and chances for reflecting the constantly elusive non-colour meanings of colours (visual or/and verbal). At least, because Eco implieis the relation 'visual and verbal colour'.

We are dealing with verbal language in so far as it conveys notions about visual experiences, and we must, then, understand how verbal language makes the non-verbal experience recognizable, speakable and effable. (1985: 159).

\section{Colour language}

My definition for Colour language is as follow: Colour language is when we express/refer to human notions and emotions, e.g. purity, anger, love, life, eternity, etc. by visual or/and verbal colour. These meanings I call non-colour meanings of colours.

The biggest difficulty is to prove the realistic parameters of the language of colours.

I am not interested in the regular referential scope of BCTs in one or another language. I am focused on a much more difficult area - to prove that colours have communicative power to refer to non-colour meanings.

If we take into account that diachronic changes are the stronghold of permanent semiosis in which some meanings remain unchanged, e.g. 'pure' (White), the conclusion of van Leeuwen is seen in a different light.

There has never been a single language of colour. Colour codes with a restricted semantics have always proliferated, and sometimes contradicted each other. But there are also broader, longer lasting, and more widely distributed trends, such as the reign of 'puritan black' or the ascendance of blue. (van Leeuwen 2011: 97).

Others call colour language something that does not meet the genuine idea of a language (a sign system) and the complexity of a 'cultural unit'. They remain in the territory of examining for BCT, including all developments of Berlin and Kay's theory on the naming and categorisation of colour, without paying attention to the fact that BCT are a small part of the ways in which each language names colours.

Actually, a real semiotic challenge is the translation between visual and verbal colour language (Kurdis 2016). 


\section{Universality}

In my writings, the term Universality differs from the evolutionary interpretation in the paradigm of Berlin and Kay. I seek to prove that there are non-colour meanings of visual and verbal colours in folk and religious rituals, e.g. purity, clean, immaculate for White; love, hate for Red; life, calm, rest for Green, etc. In the humanitarian tradition this kind of meanings is known as symbolism (Turner 1985). I claim, unlike Van Leeuwen (2011), that there is a colour language, with a small kernel of universal meanings.

\section{Prototypes in visual, verbal and cultural space. Universality}

The prototypes are the same for all mankind, in all ages, regardless of religion, level of technology and social set-up. The prototypes are the visual colours of blood, fire, sky, sea, etc. The Test for Free word associations of Kent and Rossanoff (1910) is a well-known method. The Bulgarain Norm of Free word associations for BCT (Almalech 2001; 2011a) proves that in the kernel of the Norm the most frequent and steady associations are the tokens for Prototypes.

The results of the Bulgarian Norm show that the biggest statistical frequency in the norm belongs to the terms of prototypes and mostly of their specific qualities - Almalech, 2001; 2011b). If we recall the main folklore and ritual meanings of colours (Almalech, 1996), we shall see that there is a small kernel of shared meanings. This kernel represents the universal non-colour meanings of colours. I made an experiment - I tested students from different countries (Bulgaria, Cyprus, Greece, Estonia, Finland, Italy and Kazakhstan) using English as the common language. It happened twice - during the intensive Erasmus program Semiotic Theories and Practices in Cyprus University of Technology (2014) and at Early Fall School of Semiotics (2015). Despite the fact that the students did not use their mother tongue, the responses to English BCT showed the same result - the words for Prototypes had the highest frequency.

The responses are considered (linguistic and non-linguistic, conscious and unconscious) knowledge of the universal, prototype-based meanings of colours. Rosenzweig (1961: 359-360) marks the universal character of word-associations in the frame of the Kent-Rosanoff' list across French, English, Italian and German Norms of Free Word Associations. The shared knowledge of universal non-colour meanings of BCT represents a common code - the language of colours. 
The paradigm of responses has the ability to mirror personal subconscious knowledge based on individual experience plus socially formed meanings. That is why the list of word-associations represents both the universal and the non-universal meanings of colours.

Thus, it is possible to claim that colour language, where it exists, is the semantisation and culturisation of the prototypes. Here there is a basic lexical meaning of colours - pure, clean, immaculate for light, snow and milk (White); hot, warm for fire, blood (Red); fresh, life for all plants (Green); expanse, vastness, infinitude for sky, sea (Blue), etc. Actually, this point in colour language is an universal. These basic lexical meanings get fouled by derived meanings depending on the strategy of the ritual or/and by novel context.

\section{Relativity}

In the Internet, fashion, and everyday life, the basic principle is the opposite, just as in the American Indian cultures - 'be different', 'be unique'. Pantone Inc. is a corporation known for its System (PMS) and colour chart. Every year Pantone introduces a 'colour of the year', a very influential proposition in the fashion industry, e.g. Marcala is the colour of 2015, Rose Quartz and Serenity are the colours of 2016, etc.

In some ads, logos (Apple Macintosh vs. Apple Records of Beatles) or packages (Nina Ricci fragrance bottles of Nina, Luna, etc.), symbols of traditional culture and specific colours are extensively used.

\section{Conclusion}

I think that the prototypes are the cognitive, semiotic and cultural interface between the visual and verbal colours. 